\title{
THE DIMENSION OF NORMATIVITY IN INFORMAL SOCIAL RELATIONS
}

\author{
GRETI-IULIA IVANA1
}

\begin{abstract}
The aim of this article is to discuss the character of regularities occurring in informal social bonds, be they friendships, romantic partnerships, competitions or rivalries. Since Simmel's work is emblematic for the theme of social norms involved in durable informal bonds, I take his original concept of forms of association as my point of reference. The argument I propose challenges several of Simmel's assumptions, namely his objectivist stance, his formal sociology and the autopoiesis of systems of reciprocal effects. Based on this critical rereading of Simmel, I introduce the concept of "socially constructed typical bonds" as a more dynamic and versatile alternative to the static patterns of forms of association. By bringing a subjectivist turn (inspired by Berger, Luckmann and Butler) to Simmel's forms of association, I argue for the recognition of the blurry, diverse and contradictory understandings of the typical social bond as the ground for relational normativity.
\end{abstract}

Keywords: social bonds, form of sociation, normativity, phenomenology

The theoretical problem of the regularities of social life, be they framed as social norms, values, social order, morality, has haunted writers and readers of sociology alike for over two centuries. Finding one's way through a literature of the richness, diversity and density of the Amazonian Jungle is already a great task, let alone saying anything innovative in relation to it. However, as it often happens with many aspects of social theory, I believe a great entry point is constituted by the work of Georg Simmel, and there are two reasons for it. The first is the originality of Simmel's analytical approach to the social world, and I am referring here mainly to his pivotal role in setting up a relational approach in sociology. The second is the long-term neglect of Simmel in some agenda-setting scholarly circles. While in the United States his work was more popular than in Europe in the first half of the $20^{\text {th }}$ century especially due to his influence on

\footnotetext{
${ }^{1}$ Uppsala University, Department of Sociology, email: greti-iulia.ivana@soc.uu.se.
} 
the Chicago School (mostly Parks) and the New School (mostly Schütz), this influence faded away, particularly as a result of Simmel's ideas not being discussed in Parsons' "The Structure of Social Action" (Levine et al., 1976, Levine, 1991). In Europe, a mixture of his courageous, but often uncomfortable ideas and the unfavorable historical context, made his work even less known than in the US for most of the 20 ${ }^{\text {th }}$ century (Frisby, 1992). This situation blocked many of Simmel's nascent ideas in incipient phases and left an important part of his heritage underexplored.

Over the last decades, a number of accomplished academics, like Levine in the US, Frisby in the UK and Rammstedt in Germany (Cantó Milà, 2005: 14) established Simmel's work as one of the foundational contributions for a variety of sociological subfields and traditions, ranging from structuralism (through his forms of association), symbolic interaction (through his attention to detail and the unfolding of everyday life), to urban sociology (through his depictions of the city), the sociology of emotions (through his views on love, faithfulness etc.), social inequality (the poor) or migration (the stranger). This re-popularization of Simmel, or the so-called Simmel renaissance (Blegvad, 1989), meant systematic efforts and has had great success in tracing a variety of current developments back to Simmel and in familiarizing the uninitiated social researchers with his work. However, the previous lack of attention towards Simmel's work has been counterbalanced by what is, in my reading, a sort of Simmelian orthodoxy. It was, perhaps, not only an understandable, but also a necessary approach to point out his remarkable contributions. Yet, with these steps having been taken, the moment has come, I argue, to not only trace existing theories back to Simmel, but also to build on his own work, to challenge it, to adapt it, in awareness of its strengths and limitations. This path will reveal not only the facets of Simmel's thought that managed to influence sociology (despite him often not getting the credit for it), but also, and more importantly, ways of adapting his theory and allowing it to generate new insights.

One of the seeds that Simmel planted and never gained its deserved attention in sociology is the attention paid to the social bond, to that which ties people together. This statement might look unusual, when thinking of the amount of work that has been done on themes like social relations, social interactions or the link between selves and others. Yet it is my conviction that very few of these follow Simmel's thought. The main point of rupture with Simmel's social bond is the disregard of relational stability, in favour of an analysis either of situational sequences of togetherness (Blumer, 1969; Goffman 1959, 1961 or Garfinkel, 1967) or of measurable behaviours considered as the material that constitutes social bonds and their distances (Granovetter, 1973; Marsden \& Campbell 1984; Gilbert \& Karahalios 2009; Grabowicz et al., 2012). 
Behind both of these approaches there is a common conceptual confusion: that between a social interaction and a tie or a bond. It is a distinction that, although not elaborated upon, is signalled in Simmel's ([1908] 2009) work by the use of the concepts Wechselwirkungen (for interconnected actions and effects) and Wechselbeziehungen (for interrelations). Despite the fact that the difference between the two concepts is intuitively accessible, they are at best not discussed in relation to each other and at worst used interchangeably. And given the empirically observable character of social interactions in concrete behaviours, it is often the case that the analysis of social interactions takes over the category of social relations, not the other way around.

In order to avoid this pitfall, I will go on to clarify the ways in which the two concepts are used during the course of this text. Drawing on Schütz (1967) I understand social interactions as instances where the actions of a particular social actor are either directed towards communicating certain contents to another actor, or read by the other actor as addressed to him/her. The actors need to take each other for granted as capable of acting meaningfully and as capable of interpreting each other's actions as meaningful. These conditions are typically met in contexts of copresence, but they can also occur in letter writing, phone conversations or e-mails. Social interactions are discrete, recurrent events. The regularities which are inherent in social interactions and which constitute normativity at this level are derived from the presentational character of the social self, as Rawls (1987) points out following Goffman (1961, 1983). This shapes interaction in terms of making a good showing in a given situation, managing conversations with the other or avoiding discomfort or distress for those involved.

Social bonds, on the other hand, transcend the concrete situations of communication between social actors. They are observable through interactions, but they are more than the sum of these interactions. While it is very difficult to draw precise lines about when a social bond is established or when it stops, it is sound to assume no bond emerges between two people who meet for the first time in an elevator and talk about the weather in an attempt to avoid an embarrassing silence (for a discussion about the constraints of the interaction order, see Goffmann 1983 and Rawls 1987, 1988, 1989). The reason why such an assumption sustains itself is that, besides the social interactions, there are other elements that enter in the construction of a social bond. Namely, I am referring to the reciprocal emotional investment (i.e. love, trust, respect), the construction of certain expectations about the other's future actions, the construction of a horizon of possibilities about what the other would or would not be capable of doing and the reciprocal consequences the ones who are bonded have had and expect to have on each other's lives. While interaction 
order is described above as sui genesis and relying on certain particularities of the self as inherently social, normativity in social bonds is more complex. On the one hand, we can link the rules and patterns of bonds with those of interacting and with characteristics of selves. On the other hand, we must account for the fact that social bonds are shaped in previous experience with the other, and in (more or less clear) social scripts that describe what a particular bond is, how people should behave towards each other as part of the bond or what they should feel about each other by virtue of their bond. From this point of view, the behaviours of those who are bonded form a system that is meaningful only through the lens of the bond. It does not make sense for me to go out on a day when I am not feeling well because someone else wants me to go, unless they invited me and we are friends. In that case, friendship itself makes our actions concerted and constitutes a sufficient "because motive" (Schütz, 1967) for me to go out. The bond insures the elements of action that Parsons ([1937] 1966: 75) would call "normative", by legitimizing action that has otherwise no particular purpose. Furthermore, it legitimizes not only a certain action in a given context, like a norm of interaction would, but it legitimizes an entire constellation of stable expectations and emotions towards another.

As Parsons himself pointed out (quoted by Levine, 1991), Simmel's theory cuts through his own. By this statement, he refers, most likely, to his interest in systems of action, in which a normative dimension is included, in comparison with Simmel's approach which is focused on the normative dimension itself, through forms. Parsons places human action and interaction in the centre of his theory and he seeks to explain it at least partially through the means of a shared basis of normative order. However, restating the critique brought forth by Habermas $(1987,1996)$ and Strydom (2001), Vanderstraeten (2002) points out that Parsons' solution to double contingency, and consequently, his stance on social order is rooted in a "past-oriented, objectivist and reified concept of culture" (Vanderstraeten 2002: 83). The limits of Parsons' vision become evident when we shift our emphasis from the analysis of action to an analysis of norms in themselves while still maintaining Parsons' concept of common culture. In doing so, we are confronted with questions about the emergence and functionality of norms, which a theory of social action cannot account for. Simmel's forms of association, on the other hand, are an analytical tool designed precisely for the study of social regularities as such, not as background for a system of action. Looking at norms (like Parsons) as a means of understanding the (inter)actions they inform necessarily requires us to take them as fragmented and frozen in the shape they had when manifested in a particular context, in a given moment of time. Taking social norms (like Simmel) as the object of study reveals their emergence, their continuities and disruptions in shaping a variety of interactions. In other words, Simmel does not subordinate his structuralist analysis to a functionalist 
one. I will come back to the specifics of Simmel's theory, with its advantages and shortcomings, but at this point it must be affirmed that I consider his nonfunctionalist structuralism to favour a depiction of norms as dynamic, processual, relational, although Simmel's theory does not always present them as such.

The need for a conceptualization of social norms which accounts for their emergence and flexibility has also been remarkably covered by authors writing in a post-structuralist vein, from Foucault to Butler, yet both their theories are centred on the level of the laws/ institutional order, and less on informal normativity, on the one hand, and on subjectivity, rather than bonds, on the other. So, the agenda of this article is Simmelian rather than (post)Parsonian also in this respect. Thus, the current argument is developed as an analysis of the social norms which shape and are shaped by the behaviour of social actors through bonds, not as an analysis of the behaviour of bonded social actors which is conditioned by norms.

My seeking of a way of looking into social norms as non-reified, processual, might lead one to link the position I am adopting with Luhmann's system theory, which is not as static and not as reliant on social actors. Unlike Parsons, Luhmann (1995) regards double contingency as something that cannot be overcome in social interactions, which ultimately presupposes contact between two autonomous systems, non-reducible to each other. Thus, rather than on action, he insists on communication as a generator of order, as frail and sensitive as it might be. Yet, as Rawls (1988) points out in her response to Fuchs (1988), "for Luhmann copresence [...] provides the organizational centre for interaction." (Rawls, 1988: 126). This brings me back to the earlier distinction between social interactions and ties and bonds. And if we are to accept bonds as different from, and more durable than social interactions, than our understanding of social norms needs stability as much as it needs to avoid reification. It is this stability of norms which I believe is lacking from Luhmann's work and which makes it less suitable for a discussion about social bonds.

The normativity inculcated in informal social bonds (e.g. the norms/ rules/expectations in a romantic partnership or in a friendship, by which I mean neither the legal norms, nor the norms which shape a particular interaction with the other), although touched upon in many ways, has been a peripheral preoccupation for most social theorists and it continues to be so, even after the revival of Simmel's ideas. As I mentioned above, Simmel's approach to the norms involved in social bonds is not always open and flexible, but it does have two merits: 1) that it discusses the normativity of durable social bonds to begin with, and 2) that it leaves room for his approach to be opened and given flexibility. Let us take a closer look of his theory about the patterns and regularities of bonds. 
While Simmel never offers an unequivocal definition of his forms, he does discuss them extensively. Synchronized with the themes of his time, Simmel's theory is grounded in the need to establish sociology as a distinctive science with the purpose of studying society. Society is understood as unity, resulting from the interconnectedness of its elements (yet unlike in Luhmann's system theory, this unity transcends copresence). Be that as it may, society was already the object of study of various fields. In an attempt to circumscribe a more specific disciplinary scope that does not collide with pre-existing social sciences, Simmel proposes sociology as the study of forms of association. For him, a sociological systematic analysis of the social world requires a differentiation between forms and content, although what is given to us empirically is only society as unity. Simmel ([1908] 2009) describes content as:

everything that exists in individuals, the immediate concrete locus of every historical reality - such as impulse, interest, purpose, predisposition, psychological state, and incitement in such a way as to say that on account of them people affect one another and are in turn affected. (Simmel [1908] 2009: 23)

Forms are just as diverse and, as Levine $(1981,1991)$ notes, they can be broken down in many subcategories, following the terminology of contemporary sociology:

In the collection of sociological essays Simmel assembled in the great Soziologie, he included such disparate topics as superordination and subordination (chap. 3), conflict and competition (chap. 4), the stranger and the poor person (chaps. 9, 4), secret societies (chap. 5), group expansion and the development of individuality (chap. 10), and the quantitative aspects of groups (chap. 2). [...] The study of social forms, following Simmel, can focus on relationships, or interaction processes, or roles, or collectivities, or developmental patterns, or structural variables. (Levine, 1991: 1106)

What is relevant for the present argument is that form is an abstraction meant to capture, among other aspects, the regularities that structure what I have previously defined as a social bond. A form is that which shapes reciprocally directed behaviours of social actors, but also their expectations, their emotional investment, and their way of making sense of the other and of the boundaries of what one shares with the other. In one of the clearest descriptions of forms, Simmel affirms: 
[The area of forms] may be called "pure sociology", which abstracts the mere element of sociation. It isolates it inductively and psychologically from the heterogeneity of its contents and purposes, which, in themselves, are not societal. It thus proceeds like grammar, which isolates the pure forms of language from their contents through which these forms, nevertheless, come to life. (Simmel 1950: 22)

Here, he compares forms to grammar, elsewhere to geometrical abstractions, both comparisons indicating on the one hand the abstract, purely analytical differentiation between form and content, and the empirically graspable manifestation of forms through the way in which they structure content, or life, to use his later terminology. Yet, these comparisons end up creating ambiguity more often than not. One instance of such ambiguity is the oscillation between the objectification of forms, by their divorce from the contents of the minds of social actors, and the Kantian standpoint he explicitly assumes. This stance is even more unusual when taking into account that his adaptation of Kant's work to sociology starts with the assumption that, unlike in nature, in society unity is given from within, thus positioning himself at a more subjectivist angle than Kant had adopted. It is because of such ambiguities that even social thinkers who devoted themselves to understanding Simmel have difficulties theorizing forms:

But perhaps he was aware of his uncertainty concerning what "formal" sociology was designed to study; at any rate, whether aware or not, he actually was not clear in regard to the nature of the 'forms'. (Wolff, 1950: XXXIX)

Simmelian scholars often argue that his concept of forms needs clarification and that it needs organization, but that it still stands. I believe this approach is a mistake. According to Levine (1991), Simmel's work becomes vulnerable as a result of "viewing the dispositions to engage in social interaction as pre-social" (Levine, 1991: 1111), a vulnerability that was pointed out by authors as early as Durkheim. However, this is a very serious critique that has repercussions over Simmel's entire theoretical construction and brushing it under the carpet or minimizing it makes Simmelian perspectives just as vulnerable as the original work that inspired them.

When talking about forms of association as abstractions, this category relies on the very assumption that content, understood as that which is not form, is pre-social. Contents are, however, as interactionists (but also post-structuralists) have shown after Simmel, profoundly social, as they are shaped by norms of behaviour, by dominant discourses, by roles and expectations etc. One eloquent 
example in this sense is Goffman's work. Goffman's (1959) metaphor of the dramaturgy of everyday life draws on the premise that individuals take up different roles in order to create an idealized version of their selves. These roles vary according to different contexts and according to what the audience expects as appropriate behaviour. Consequently, he makes a distinction between "expressions given and expressions given off", where the latter consists of uncontrolled manifestations of the "true self". Despite bringing in the idea of a "true self" that escapes the social scenario, Goffman takes one step further than Simmel in the direction of the social nature of motivations, behaviours and intentions. To him, that which an individual tries to convey in a social context is inherently social and is originated in expectations and role taking. More concretely, an example of how the social component is present in one's motivations is the concept Goffman (1967) calls "face". Making a good showing for oneself can be, in Simmel's terms, a personal intention or wish, which manifests itself in certain patters in which reciprocal actions and effects unfold. While we can envision this intention being expressed differently in the context of friendship as compared to the context of having just met someone, the fact that "the rules of the game" are social does not mean "the stake and the unfolding of the game" are any less social.

Going even further than Goffman who still leaves "the real self" outside of social norms is Hochschild's (1979) approach to emotional management. Since emotions are probably the last bastion of imagined autonomy of the individual from the social, her arguments make a very strong case for the claim that there is nothing one feels, does, believes that is not "contaminated" by the social life he/she has had. When talking about the regulations that shape our experience, she points out that Goffman's actors actively manage outer impressions, but they do not actively manage inner feelings. On the contrary, for Hochschild $(1979,1983)$, there is an even deeper layer of control that does not imply putting on a role or a mask, but working on one's own emotion. Moreover, there are rules of social acceptance or desirability in regard to the appropriate feelings associated to certain circumstances. A socialized individual "should feel" something very specific at one time or another:

A feeling rule shares some formal properties with other sorts of rules, such as rules of etiquette, rules of bodily comportment, and those of social interaction in general (Goffman, 1961). A feeling rule is like these other kinds of rules in the following ways: It delineates a zone within which one has permission to be free of worry, guilt, or shame with regard to the situated feeling. (Hochschild, 1979: 565) 
One could argue that Goffman's social role or Hochschild's feeling rule also circumscribe a sphere of the normative, similar to Simmel's forms and, to a certain extent, they do. However, the insistence on the issue of socialization (particularly Hochschild), reveals a different character of structure: namely, structure as internalized. The implications of this approach are not only related to how structure manifests itself, but also to what structure is. And for Hochschild, feeling rules are a social construction, although still a slightly too reified one, I would argue. Simmel's forms, on the other hand start off as autopoietic social constructions, but they are necessarily reified when one makes the methodological choice of distinguishing them from content, because in doing so, one does not only miss how forms structure life, but also how they are deconstructed and reconstructed.

Form, at least in its crystallized stage, solidifies patterns. In Simmel's work, competition, subordination and all the other forms are discussed outside of lived experience. They are abstract norms according to which reciprocal actions and effects unfold. Consequently, they lack versatility. Rather, if we descend the social patterns (as well as social roles or feeling rules, for that matter) from forms to the experience of social actors, they become subject to interpretations, doubts, questions, misunderstandings and they lose their law-like status.

In a certain sense, Simmel gives the social actor plenty of freedom. One example is the following quotation:

As a result of the inherent flexibility and dislocation of our boundaries, we are able to express our essence with a paradox: we are bounded in every direction, and we are bounded in no direction. (Simmel 1971: 355)

However, it must be noted that the flexibility comes on the level of praxis, not on the formal level. He explains human life as forever bound to two poles, richness and determinacy. And forms represent determinacy. They are boundaries that we can step over, but knowing them and stepping over them, does not mean denying their existence. For Simmel, they represent the exterior, uniform, stable, and predictable layer that is filled with life. I find this metaphor of separation and given empty forms which are than paired with their corresponding events very misleading for the relation between patterns/ regularities and social reality as a whole.

Thus, coming back to the issue of contents not being pre-social, this marks an important shift that needs to be accounted for, since it means an analysis of forms of association is an analysis of social life. Simmel (1971: 351-352) himself talks about forms as fixed and as not keeping up with the dynamics of life, but 
he feels this is an appropriate depiction of the actual stability of norms. I argue that this fixity is constructed discursively through notions such as "form" to begin with. Judith Butler (1997: 88-91) points out that standards of universality must be seen through the lens of their historical articulation, for it is through that very articulation that they establish the notion of universality as substantive. Transferring Butler's argument to Simmel's relational forms, I claim that friendship and "what friends should do", or couples or competitors, are only typifications of various bonds, and the categories created this way depict an artificial unity between instances of social bonds that sometimes are not even similar. Furthermore, not only the practices of friendship, but also the idea of "what is normal" which emerges and which accompanies the practices of the social relation is not unitary either. Simmel's forms might apply to laws, but informal social bonds are far too little institutionalized for this concept to be used. In this sense, instead of forms, I argue that a better concept to serve Simmel's preoccupation for a) structure in itself (not subordinated to function) and b) for the norms that shape social relations is "the social construction of the typical social bond". This new conceptualization allows us to approach a Simmelian thematic in different and more nuanced terms. By this I mean a full recognition of the inescapably social character of every aspect of our reality and an account of normativity as an imaginary universality eternally under both subjective and objectifying construction.

Some would say that Simmelian scholars have already made significant efforts into giving flexibility and openness to the concept of forms and that proposing a new concept to capture the patterns and norms of social bonds is just terminological nitpicking. I consider it not to be, because taking the social construction of the typical bond and not the form as the focus of our study has two particular purposes: a) counter-reification of the normative element of bonds and $b$ ) building a link between the unfolding and the lived dimension of particular bonds and the meaning of the bond on a societal level (to the extent to which we can talk about something like that). In an attempt to further clarify my stance, I will now turn to a different entry point in Simmel's work, namely the one emphasizing the flowing and dynamic character of life.

It must be said that my presentation of Simmel's thought throughout this paper has been very schematic and monochrome. As Pyyhtinen (2010: 68) points out, Simmel was not particularly concerned with the consistency and accuracy of his conceptual apparatus, as he often used the same term to designate different ideas, or two different terms to describe similar situations. Furthermore, I would add, different fragments of his writings are not always compatible with each other, particularly regarding Kantian transcendental idealism and in relation to society as a web of interconnections. Faced with 
Simmel's own occasional incongruity, the emphasis on specific facets of his theory is, more often than not, a question of the reader's interpretation. One alternative interpretation from my own is the following:

Simmel regards the independent and autonomous forms of sociology as merely secondary phenomena compared with the real reciprocity/ Wechselwirkung between individuals (GSG 2: 130). In these crystallized forms, 'the forces of reciprocal effect [wechselwirkelnden Kräfte] have already withdrawn [auskristallisiert] from their immediate bearers' (GSG 11: 32). For Simmel, it is only the 'delicate, invisible threads that are spun from one person to another', not the 'final finished pattern' of society's 'uppermost phenomenal stratum' (GSG 8: 292), that constitute 'the real life of society provided in our experience' (GSG 8: 277). (Pyyhtinen, 2010: 73)

While I agree with Pyythinen that this type of distinction between form and life (or content) is representative for Simmel, I disagree about Simmel's preference for the lived over the formalized element. Simmel repeatedly stated his faithfulness towards "formal sociology" or "pure sociology" and has dedicated most of his work to discussions about forms, so at least from this point of view, forms are not secondary:

To separate, by scientific abstraction, these two factors of form and content which are in reality inseparably united; to detach by analysis the forms of interaction or sociation from their contents (through which alone these forms become social forms); and to bring them together systematically under a consistent scientific viewpoint - this seems to me the basis for the only, as well as the entire, possibility of a special science of society as such. (Simmel 1971:25)

As Fitzi (2002) shows, the fluctuating aspect of life and the fixed, objectified form are for Simmel two poles, and, from this point of view, even accepting Pyyhtinen's claim about the pre-eminence of reciprocity, processuality and events over forms, the dichotomy itself is what I am challenging with the concept of "social construction of the typical social bond".

Furthermore, replacing forms with constructions of the typical also implies incorporating elements of a Weberian view on society. Pyyhtinen (2010: 76) points out Simmel separates "the real reciprocity/ Wechselwirkung between individuals" from the individuals who live it. With Simmel, he argues, individuals do not only act, but are also affected; there is a dimension of passivity in social happenings. Life as an interconnection of reciprocities conceptualized outside of the actors acting and being affected by these reciprocities is afterwards 
crystallized into forms. I see two problems with this train of thought. One is a shift from a constructionist view of everyday life to a structuralist view derived from the concept of forms of association. The other is that for Simmel, the emergence of stability in the pre-formal stage of social bonds can only be viewed as an autopoiesis of the system of reciprocities, like it is for Luhmann (Poli, 2010: 5-6). Let us think, in a Simmelian vein of an episode where reciprocal actions and effects occur without them being shaped by a particularly crystallized form of association. That episode and very similar ones occurring after it would lead, for Simmel, to greater formalization, as a result of the self reproduction of the system of interconnections between people. The reoccurrence of similar events should not be read through the lens of how the participants to the events found them meaningful and how that meaning became gradually taken for granted, because the system of reciprocal influences is the logical unit from which we started, not the individual who is caught in the system. However, as Poli mentions: "In the end, it is fair to acknowledge that neither Parsons nor Luhmann were able to spell out the details of this major ontological problem (note: the problem of the reproduction of social systems)" (Poli, 2010: 7). To add to Poli's statement, I would say neither does Simmel's theory explain how crystallization comes about in the case of social bonds. Taking the example of "friendship" as a form of association, how can we make the step from particular events where reciprocal actions and effects are unfolding in a certain way to the crystallized form? How does this autopoiesis of the system that is the social bond work in practical terms? My claim is that understanding friendship, for instance, as a social bond with its normative dimension requires a "descent" from a form with its imagined universality into the occurrences of fluctuating life on the one hand, but also into the subjective meaning constructions from which it draws its relative stability. Put briefly, I believe that both Simmel's and Luhmann's work lack in accounting for the genealogy of the stability of bonds as a result of their objectivist stance. The outcome are norms that are either too fixed (in Simmel), or not fixed enough (in Luhmann).

At the same time, it is important to question to what extent a notion such as "the social construction of the typical social bond" maintains the Simmelian relational standpoint and to examine the risk of solipsism that comes from bringing elements of subjectivity into our conceptual apparatus. My answer is that such an addition does not take anything away from a relational approach. The focus remains on the regularities of social bonds, viewed as emerging from the flow of systems of reciprocal influences, but human consciousness becomes part of these systems as well. It is not my intention to deny the condition of passivity of human beings throughout their social life, but only to include elements of active meaning constructions beside 
that passivity. To be sure, those meaning constructions are already shaped by social norms, but they will also be shaped by individual biographies, by different ways of socialization, by exposure to various practices and they will end up being unique. These subjective ways of making sense of social bonds are actually part of a relational account of the normativity of bonds. It is because social bonds involve people that those bonds are stable, contested, reshaped, negotiated, irrational, profitable, contradictory all at the same time. As a result, I consider the view I am proposing for discussing the Simmelian agenda about the relatively stable aspects of durable social ties is relational with a subjective twist. As it might have been intuited in the course of the argument, this twist draws heavily on Berger and Luckmann's "Social Construction of Reality" (1967). The reason for my choice is their refined understanding of institutionalized/objectified social reality as part of a theory with a decidedly subjectivist foundation (Weber and Schütz). I believe this rethinking of Simmel in light of Berger and Luckmann's work solves the problem of the reification of forms, and perhaps more importantly (since it is less discussed by Simmelian scholars) the problem of the autopoiesis of systems of reciprocal actions and effects from which forms emerge.

Namely, Berger and Luckman (1967) write:

\begin{abstract}
All this (note: institutionalization in nucleo) changes in the process of transmission to the new generation. The objectivity of the institutional world 'thickens' and 'hardens', not only for the children, but (by a mirror effect) for the parents as well. The 'There we go again' now becomes 'This is how these things are done'. A world so regarded attains a firmness in consciousness; it becomes real in an ever more massive way and it can no longer be changed to readily. [...] Since they (note: the children) had no part in shaping it, it confronts them as a given reality that, like nature, is opaque in places at least. (Berger and Luckmann: 76-77)
\end{abstract}

As the authors state unequivocally in the fragment quoted above, their perspective is not proclaiming self-determining agentic subjectivity and utterly untouchable diversity at the core of the social world. They talk about an institutional order, one that even becomes objectified, but not one that is objective. Berger and Luckmann regard social order as "an ongoing human production" (idem, p. 69). This means that social norms, or in the case of this article the norms that condition social bonds, start off through repetition, habitualization and when both the actions and the actor performing them are typified in a taken for granted way, institutionalization is born. Yet, they point out this institutionalization solidifies over generations. I would add that the process of passing on institutionalizations in nucleo is not necessarily 
generationally bounded. Particular situations might become meaningful in a given way on a small scale and those meaning constructions might impose themselves fast on a community or societal level in a relatively short period of time, if let us say, the ones who generated them are in positions of power. However, power distribution is not the focus of the current argument. What I wish to insist on instead is the origin of the objectified norm. For Berger and Luckmann, like for Simmel, the norm is born from a flowing system of interdependencies. Yet, these interdependencies are mediated by meaning constructions and the actual process of normalization of otherwise contingent reciprocal influences gains its stability from those meaning constructions. From here, it follows that even if the "final product" (although Berger and Luckmann would certainly not use this syntagm) is an objective norm, its character is fundamentally different than in Simmel. Namely, the norm is constantly emerging and being reconstructed, it is not there and it is not filled.

At the same time, it is important to note the importance of typifications from the early stages of the process of institutionalization. In this respect, Berger and Luckmann's work also converges with Butler's, despite the different level of the analysis taken up. Berger and Luckmann's concept of typification draws heavily upon Schütz's earlier use of the same term. Schütz (1967) understands typification as inherent to making sense of the world. For him, any meaning construction relies on typifying, which is a linguistic mechanism. It is only by calling/thinking of an object we see as an apple that we typify it as such and view it as meaningful. Butler (1997) takes a similar stance on the issue of language in her analysis of hate speech. She writes: "[...] it is by being interpellated within the terms of language that a certain social existence of the body first becomes possible." (Butler 1997: 5) In other words, the social existence of the body is conditioned by language, because, like Schütz was claiming, language is the vehicle of typification and typification is meaning. Thus, in order for the body to be social, it needs to be meaningful (or typified). This train of thought is applied by Berger and Luckmann when talking about social relations, which also become meaningful linguistically through typifications of courses of action and of actors. From this standpoint, language does not only sustain or threaten the social existence of the body, but it does the same with the existence of the bond. These are the aspects through which I believe the concept of the construction of the typical social bond can enrich the original concept of forms of association.

Following Berger and Luckmann's (1967) view about the institutionalization of social order, I will outline some main features of socially constructed typical bonds:

1) they do not correspond to actual social bonds;

2) they are abstractions based on the typification of various empirically lived/ observed/ heard about bonds as having certain common features; 
3) they are sedimented enough that they cannot be traced back to the original meaning constructions from which they emerged;

4) they are generated subjectively and tend towards objectification when certain (inter)actions, reactions, emotional expressions that contribute to the bond gain taken for granted meanings by virtue of the existing meaningful bond (e.g. "you cheated on me, so you do not value our couple");

5) they are never entirely objectified;

6) through meaning constructions which include both particularities of a given experience of togetherness and the version of the social norms in the social actors' stocks of knowledge, bonds gain both stability and flexibility.

At the same time, we must keep in mind that the institutionalization that Berger and Luckmann talk about, as well as the construction of the sexed and gendered body in Butler's work, refer to a stronger "this is how things are done" than informal social bonds. By this, I do not mean that social bonds do not have a well circumscribed normative core, but I mean they also have something else besides this nucleus. If we take the example of the normativity embedded in couple relations, some elements of sexuality are entirely socially regulated (e.g. incest and paedophilia). In this case, both the course of action and the actor are typified in a straight forward socially homogenous way. Monogamy is not as socially regulated. Flirting is even less socially regulated. Based on an adaptation to Simmel's theory, Blatterer (2013) was writing about the relative normative freedom of friendship. My claim is that in any typical informal bond, one can distinguish layers ranging from non-negotiable social norm (the condicio sine qua non of typicality) to norms that have a status weak enough to make debatable their inclusion in the construction of typicality.

In informal social bonds, many of the norms are in this diffuse middle ground. In quotidian conversations, we often hear people worrying about whether they should end the romantic relation they are in, whether they should tell their boss how they feel about their schedule or whether to rely less on their friends. Besides the possible (inter)action norms involved in these decisions (e.g. "Is it appropriate to tell someone something unpleasant in a straight forward way?"), what is being questioned is the normativity of the bond. Does the romantic relation that the individual views as typical end over the grounds one is considering ending one's own? Do they even have a clear construction of the typical bond according to which to map the meaning of their own? If not, it is that construction that they are trying to achieve in order to understand the bond they are part of. Alternatively, opposite well solidified constructions of typical bonds can collide, challenging and reshaping what had previously been read as typical. 
Of course, not every aspect of a social relation goes through the filter of the normativity of the typical bond in order to be meaningful. Various events, emotions or doubts will be interpreted according to other frames of meaning or the normalized and regulated will come into play. Nevertheless, in this case, as in the examples above, social norms reveal themselves as nothing if not patterns of meaning construction.

\section{Conclusions}

The aim of this article has been to explore the issue of normativity in informal social bonds, insisting on the paradox of its dynamic and structured character and on its sources of freedom and stability. This approach is founded on my strongly held belief in the need for further debate on the relation between normativity and lived, nuanced experience, in the context of durable social bonds.

My contribution to this debate starts with a conceptual distinction between social interactions and social bonds and the types of normativity they involve. Social interactions are recurrent events occurring between individuals who direct their actions at each other and who take each other for granted as meaning makers. Social bonds involve durable connection between human beings who, with or without copresence, are linked by emotions, expectations, memories of past common experiences, imaginaries about each other or future plans that involve the other. If the interaction order can be considered sui genesis and based on the ritual nature of selves, the patterns of bonds appear to us as social scripts and hypostases of "what is normal", which cannot be accounted for only in terms of the presentational character or the need for sociality of selves.

Setting out to explore the issue of normativity in the patterns and regularities of durable informal social bonds connects the argument of this article with discussions on forms of association, double contingency and social order. In relation to this field, I place my text according to several coordinates. Namely, I argue for an analysis of normativity in social bonds with certain durability, not episodic interaction. I am interested in the patterns of informal relations, not in the constructions of subjects or of order at the institutional level. I am focused on regularities in social bonds, their emergence, their flexibility and fixity, and their contestation, not on the role or application of norms as 'ingredients' of social action. By making these choices, I position myself in the vein of Simmelian sociology.

However, the core of my argument states that there is a need to reconceptualize Simmel's forms of association in order to achieve a more versatile, more grounded and more transparent understanding of regularities 
and their normative character in durable social bonds. Firstly, one of the main ideas I challenge in Simmel based theory is the dichotomy between forms and content/life and the consequences of this dichotomy on interpreting patterns within social bonds. My claim is that once we have reached an agreement over the social conditioning of every aspect of our lives, any dichotomy based on formalization loses its meaning. Secondly, when thinking of social regularities as emergent from reciprocal influences and effects between various forces, another side of Simmel's work that I believe needs to be questioned is the implied autopoiesis of social systems. Thirdly, I regard both the first and the second points as stemming from a problematic objectivist stance towards social reality.

As a consequence of this analysis, I propose the Berger and Luckmann inspired concept of social construction of the typical social bond as a more suitable notion than forms of association for capturing the subjectively informed objectivity under construction that makes up for the norms of durable social bonds. While I believe many Simmelian scholars embrace this view, there is a certain reluctance in replacing the original terminology of formal sociology. This reluctance results in a perpetuated ambiguity and in a constant tendency of theoretical reification of fluid empirical phenomena which come hand in hand with an uncritical reading of the initial conceptual apparatus.

\section{REFERENCES}

Berger, L. Peter and Luckmann Thomas (1966). The Social Construction of Reality, Anchor Books.

Blatterer, Harry (2013). 'Friendship's Freedom and Gendered Limits', European Journal of Social Theory, 16 (4), pp. 435-456.

Blegvad, Mogens (1989). 'A Simmel Renaissance' [Review of the book Soziologie und Erkenntnistheorie bei Georg Simmel by Horst Jürgen Helle]. Acta Sociologica, 32 (2), pp. 203-209.

Blumer, Herbert (1969). Symbolic Interactionism: Perspective and Method, Englewood Cliffs, N. J.: Prentice-Hall.

Butler, Judith (1997). Excitable Speech: A Politics of the Performative. New York and London: Routledge.

Cantó-Milà, Natàlia (2005). A Sociological Theory of Value. Georg Simmel's Sociological Relationism. Transcript-Verlag.

Fitzi, Gregor (2002). 'Comment la société est-elle possible? Développement et signification du 'paradigme épistémologique' de la Sociologie de Simmel de 1908', in L. Deroche-Gurcel und P. Watier (Hg.), La Sociologie de Simmel (1908). Éléments actuels de modélisation sociale, PUF, Paris.

Frisby, David (1992). Simmel and Since. Essays on Georg Simmel's Social Theory. London and New York: Routledge. 
Fuchs, Stephan (1988). 'The Constitution of Emergent Interaction Orders: A Comment on Rawls', Sociological Theory, 6(1), pp. 122-124.

Garfinkel, Harold (1967). Studies in Ethnomethodology. New Jersey: Prentice-Hall.

Gilbert, Eric and Karahalios, Karrie (2009). 'Predicting Tie Strenght With Social Media', CHI '09 Proceedings of the SIGCHI Conference on Human Factors in Computing Systems, pp. 211-220.

Goffman, Erving (1959). The presentation of the self in everyday life (2nd Ed.). New York, NY: Anchor Books.

Goffman, Erving (1961) Encounters. Indianapolis, Indiana: Bobbs Merrill.

Goffman, Ervin (1967). Interaction Ritual: Essays on Face- to-Face Behavior. Anchor Books.

Goffman, Erving (1983). 'Presidential Address: The Interaction Order', American Sociological Review, 48, pp. 1-17.

Granovetter, S. Mark (1973). 'The Streght of Weak Ties', American Journal of Sociology, 78 (6), pp. 1360-1380.

Grabowicz, A. Przemyslaw, Ramasco J. José, Moro Esteban, Pujol, M. Josep, Eguiluz, M. Victor, (2012). 'Social Features of Online Networks: The Strenght of Intermediary Ties in Online Social Media', PLoS ONE, 7 (1), pp. 1-10.

Habermas, Jürgen (1987). The Theory of Communicative Action, Vol. 2. Boston: Beacon. Habermas, Jürgen (1996). Between Facts and Norms. Cambridge, MA: MIT Press.

Hochschild, Arlie Russell (1979). 'Emotion Work, Feeling Rules, and Social Structure', American Journal of Sociology, 85 (3), pp. 551-575.

Hochschild, Arlie Russell (1983). The Managed Heart. Commercialization of Human Feeling. Berlekey: University of California Press.

Levine, Donald N., Ellwood B. Carter and Eleanor Miller Gorman (1976). 'Simmel's Influence on American Sociology I', American Journal of Sociology, 81 (4), pp. 813-845.

Levine, Donald N. (1981). 'Sociology's Quest for the Classics: The Case of Simmel', pp. 60-80 in The Future of the Sociological Classics, edited by Buford Rhea. London: Allen \& Unwin.

Levine, Donald N. (1991). 'Simmel and Parsons Reconsidered', American Journal of Sociology, 96 (5), pp. 1097-1116.

Luhmann, Niklas (1995). Social Systems. Stanford: Stanford University Press.

Marsden, V. Peter and Campbell E. Karen (1984). 'Measuring Tie Strenght', Social Forces, 63 (2), pp. 482-501.

Parsons, Talcott (1966) [1937]. The Structure of Social Action. A Study in Social Theory with Special Reference to a Group of Recent European Writers, New York: The Free Press and London: Collier- Macmillan Ltd.

Poli, Roberto (2010). 'The Complexity of Self-reference. A Critical Evaluation of Luhmann's Theory of Social Systems', Journal of Sociocybernetics, 8 (1), pp. 1-23.

Pyyhtinen, Olli (2010). Simmel and 'The Social'. Palgrave Macmillan.

Rawls, Anne Warfield (1987). 'The Interaction Order Sui Genesis: Goffman's Contribution to Social Theory', Sociological Theory, 5 (2), pp.136-149.

Rawls, Anne Warfield (1988). 'Interaction vs. Interaction Order: Reply to Fuchs', Sociological Theory, 6 (1), pp. 124-129. 
Rawls, Anne Warfield (1989). 'Simmel, Parsons and the Interaction Order', Sociological Theory, 7 (1), pp. 124-129.

Schütz, Alfred (1967). Phenomenology of the Social Word. Evanston, Illinois: Northwestern University Press.

Simmel. Georg (2009) [1908]. Sociology: Inquiries into the Construction of Social Forms. Vol. I and Vol. II. Anthony J. Blasi, Anton K. Jacobs and Mathew Kanjirathinkal (Eds.\& Trans.), Boston: Brill.

Simmel, Georg (1950). The Sociology of Georg Simmel. Kurt H. Wolff (Ed.\& Trans.), The Free Press.

Simmel, Georg (1971). On Individuality and Social Forms. Donald N. Levine (Ed.). Chicago and London: The University of Chicago Press, The Heritage of Sociology Series.

Strydom, Piet (2001). 'The Problem of Triple Contingency in Habermas', Sociological Theory, 19 (2), pp. 165-86.

Vanderstraeten, Raf (2002). 'Parsons, Luhmann and The Theorem of Double Contingency', in Journal of Classical Sociology, 2 (1), pp. 77-92.

Wolff, Kurt Heinrich (1950). Introduction. In Kurt Wolff (Ed.\&Trans.) The Sociology of Georg Simmel. Free Press. 